Rнорм, что можно увидеть в таблице 1. По данным этой таблицы можно сделать выводы, что из выбранных нами зданий ни одно не подходит под условие санитарногигиенического требования для стен, зато окна полностью соответствуют данному условию (вследствие того, что практически все окна заменены на пластиковые), они не пропускают тепла из жилых квартир. Так же, при рассмотрении этой таблицы можно заметить, что при сравнении фактического сопротивления теплопередаче и допустимого сопротивления теплопередаче в некоторых домах не соблюдаются условия. К примеру, по адресу Ойунского 2 можно заметить, что теплопередача Q меньше чем допускаемое сопротивление теплопередаче R0, следовательно, санитарногигиеническое условие соблюдается. Сравним полученные данные для нового здания по адресу ул. Сосновая 6, по которым видно, что теплопередача от внутренней поверхности стены к наружной больше, чем допустимое и нормируемое сопротивление теплопередачи, а значит условие не выполняется. Так же видно по адресам Аммосова 14/1, Карла Маркса 7, Дружба Народов 18/1, что теплопередача Q наружных стен жилых помещений меньше чем допустимое R0 и нормируемое Rнорм сопротивление теплопередачи, условие выполняется. По результатам исследования можно сделать вывод о том, что в г. Нерюнгри здания, построенные в 80-90-х гг., имеют низкие теплопотери, чего нельзя сказать о ранее построенных домах, где теплопередача выше установленной нормы.

Список литературы:

1. СП 131.13330.2012 Строительная климатология. Актуализированная редакция СНиП 23-01-99* (с Изменением N 2).

2. СП 50.13330.2012 Тепловая защита зданий. Актуализированная редакция СНиП 23-02-2003.

3. СП 109.13330.2012 Холодильники. Актуализированная редакция СНиП 2.11.02-87.

\title{
Особенности организации зимнего содержания автомобильных дорог в городе
} Якутске

\author{
Макаров В.С., студент, \\ Северо-Восточный федеральный университет, \\ 2. Якутск \\ E-mail: mr05vma@gmail.ru
}

Научный руководитель: стариий преподаватель Макаров Н.М.

Под зимним содержанием автомобильных дорог и городских улиц понимается комплекс мероприятий, который включает [1, стр. 3]:

- защиту дорог и улиц от снежных заносов;

- очистку от снега;

- борьбу с наледями;

- борьбу с зимней скользкостью. 
Зимняя скользкость - снежные отложения и ледяные образования на поверхности дорожного покрытия, приводящие к снижению коэффициента сцепления колеса автомобиля с поверхностью покрытия [2, стр. 3].

Основной задачей зимнего содержания является обеспечение постоянного и безопасного движения автомобилей со скоростями, установленными для данной категории автомобильной дороги. Данная задача решается по трем направлениям: улучшение сцепления колеса автомобиля с поверхностью дорожного покрытия, удаление снежных отложений и ледяных образований с поверхности дорожного покрытия, а также предотвращение образования скользкости. Существует 3 способа борьбы с зимней скользкостью:

1) распределение химических, фрикционных или комбинированных противогололедных материалов по поверхности дорожного покрытия;

2) тепловой способ;

3) механический способ.

Механический способ борьбы с зимней скользкостью предусматривает использование самоходных и прицепных машин и механизмов ударного, скребкового, вибрационного или срезывающего действия для разрыхления и отделения льда и уплотненного снега от покрытия.

Тепловой способ заключается в удалении снежных и ледяных отложений путем подогрева покрытий нагревательными элементами, закладываемыми в покрытия и удаление снежно-ледяного слоя с покрытий с помощью тепловых машин.

В городе Якутске в качестве способа борьбы с зимней скользкостью используется метод подсыпки фрикционного противогололедного материала - песка. Противогололедные материалы (ПГМ), это химические (твердые сыпучие, жидкие), фрикционные (мелкий щебень, песок, песчано-гравийная смесь, шлак, золы уноса) или комбинированные (смесь химических и фрикционных ПГМ) дорожноэксплуатационные материалы, применяемые для борьбы с зимней скользкостью на автомобильных дорогах. За 2016 год в городе Якутске было подсыпано около

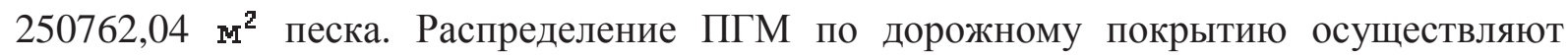
специальными распределителями, один из которых изображен на рис. 1.

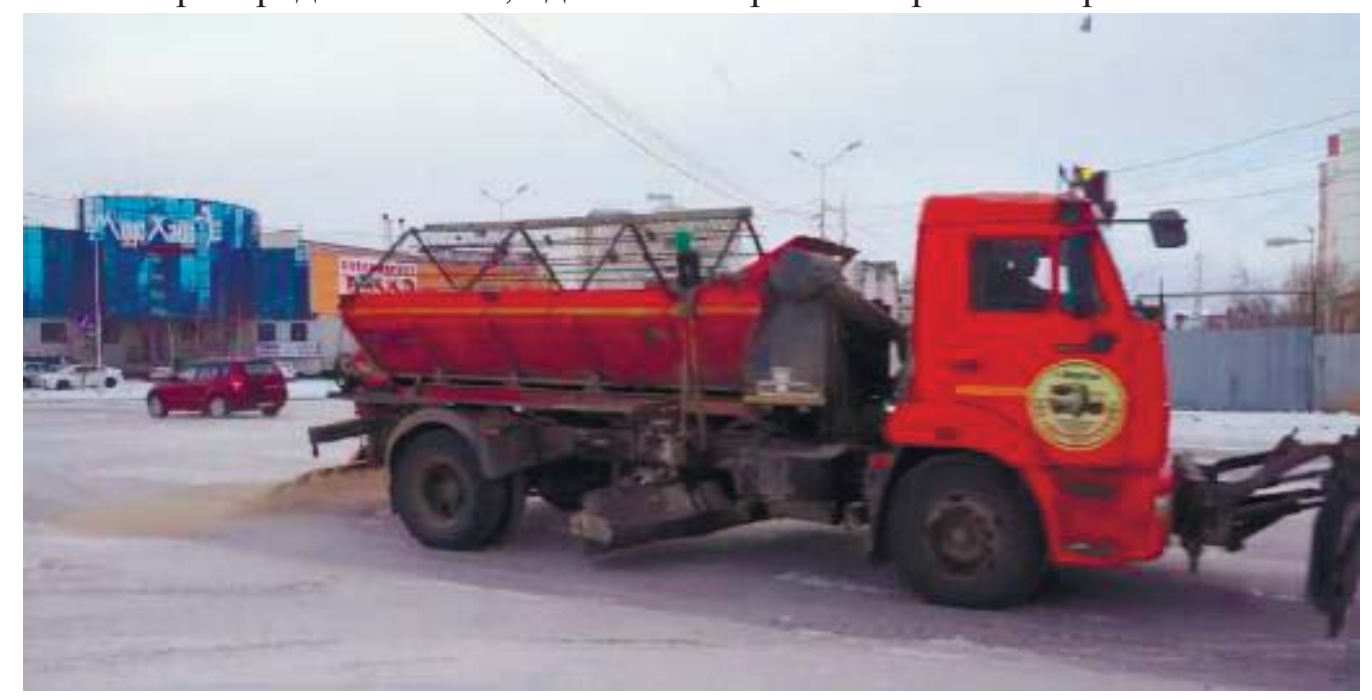

Рис. 1. Распределитель фрикционного ПГМ 
Сроки ликвидации зимней скользкости и окончания снегоочистки для автомобильных дорог, а также улиц и дорог городов и других населенных пунктов с учетом их транспортно-эксплуатационных характеристик приведены в табл. 1 [4, стр. 4].

Таблица 1

Сроки ликвидации зимней скользкости

\begin{tabular}{|c|c|}
\hline $\begin{array}{l}\text { Группа дорог и улиц по их } \\
\text { транспортно-эксплуатационным } \\
\text { характеристикам }\end{array}$ & $\begin{array}{l}\text { Нормативный срок ликвидации зимней } \\
\text { скользкости и окончания снегоочистки, } \\
\text { ч }\end{array}$ \\
\hline$>3000$ авт/сут. & 4 \\
\hline 1000 до 3000 авт/сут. & 6 \\
\hline$<1000$ авт/сут & 5 \\
\hline
\end{tabular}

Согласно руководству по борьбе с зимней скользкостью на автомобильных дорогах [3, стр. 14], нормы расхода фрикционных ПГМ назначают в зависимости от интенсивности движения, указанных в табл. 2.

Таблица 2

Нормы расхода фрикционных ПГМ

\begin{tabular}{|c|c|}
\hline$<500$ авт./сут. & $100-150$ г/M2 \\
\hline $500-1000$ авт./сут & $150-250$ г/M2 \\
\hline $1000-3000$ авт./сут. & $250-400$ г/м2. \\
\hline
\end{tabular}

Для того, чтобы определить какие нормы подсыпки фрикционных ПГМ необходимо применять на улицах города Якутска, было произведено исследование интенсивности движения на одном из перекрестков города, а именно на пересечении улиц Лермонтова, Красильникова и Сергеляхское шоссе. Максимальное значение интенсивности наблюдались днем, и составило: 06.03.2017 - Na=2899 авт./час.

При сопоставлении полученных значений интенсивности движения с таблицей 1 получаем, что в городе Якутске необходимо подсыпать 250 - 400 г/м² песка, однако МКУ «СЛУЖБА ЭКСПЛУАТАЦИИ ГОРОДСКОГО ХОЗЯЙСТВА» совместно с Окружной администрацией города Якутска согласовали норму в размере $1000 \Gamma / \mathrm{M}^{2}$, так как принятого в «Руководстве по борьбе с зимней скользкостью на автомобильных дорогах» [3, стр. 15] расхода недостаточно при использовании в суровых климатических условиях Якутии.

В ходе наблюдения за перекрестком было замерено время, за которое песок разносится проезжающими автомобилями, на рассматриваемом перекрестке это заняло 18-20 часов рисунок 2, после чего песок с полос наката был удален полностью и не мог способствовать торможению. 


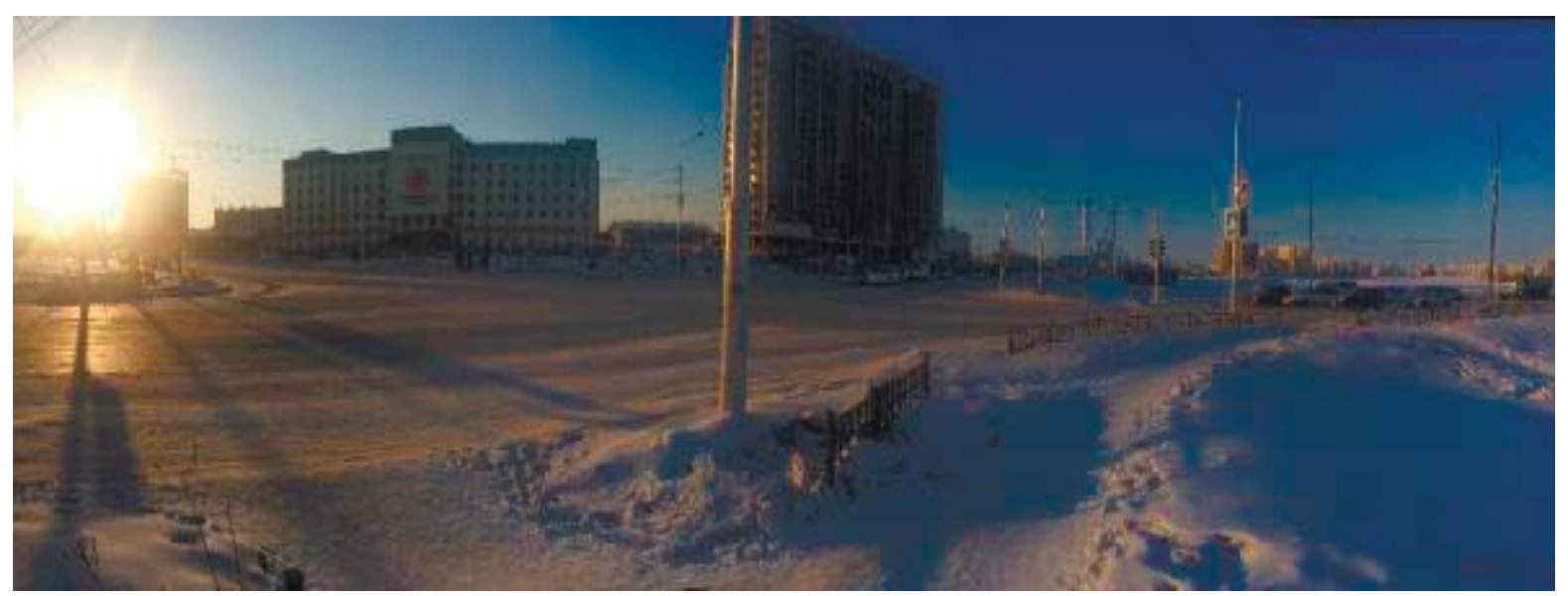

Рис. 2. Вид перекрестка через сутки после подсыпки песка

Также, наблюдения велись за проезжей частью по улице Стадухина. В данном месте песок удалился с поверхности дорожного покрытия за 2 часа.

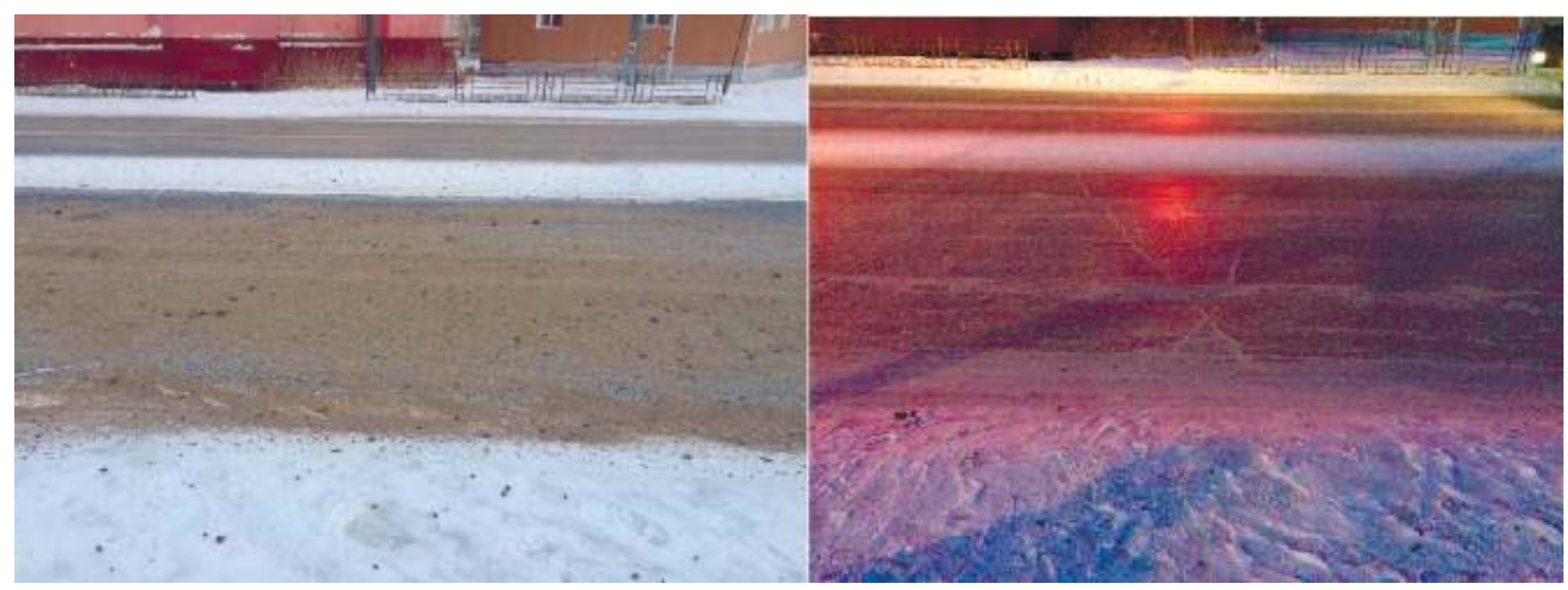

Рис. 3. Вид проезжей части сразу после подсыпки песка и через 2 часа после подсыпки

Исходя из данного исследования, можно сделать следующие выводы:

1. Необходимо найти способ задержки ПГМ на дорожном покрытии.

2. Измерить фактический расход песка распределителями на м²

3. Проверить зависимость удаления ПГМ от интенсивности движения.

\section{Список литературы:}

1. Обзорная информация Автомобильные дороги и мосты. Противогололедные материалы для борьбы с зимней скользкостью на автомобильных дорогах и городских улицах. Обзорная информация. Выпуск 4

2. ОДМ 218.5.006-2008 «Методические рекомендации по применению экологически чистых антигололедных материалов и технологий при содержании мостовых сооружений».

3. Руководство по борьбе с зимней скользкостью на автомобильных дорогах.

4. ГОСТ Р 50597-93 «Автомобильные дороги и улицы. Требования к эксплуатационному состоянию, допустимому по условиям обеспечения безопасности дорожного движения». 


\title{
Программное средство расчета оснований фундаментов при использовании многолетнемерзлых грунтов в качестве оснований по I принципу
}

\author{
Назаров Т.А., Бочуров В.Б., магистранты, \\ Северо-Восточный федеральный университет, \\ 2. Якутск \\ E-mail: Nazarovta@yandex.ru; \\ baaska1995@gmail.com
}

\section{Научный руководитель: к.т.н., доцент Посельский Ф.Ф.}

В настоящее время в системе автоматизированного проектирования (САПР), существует проблема отсутствия программного обеспечения расчета оснований и фундаментов на многолетнемерзлых грунтах. Сейчас в Якутии для расчета несущей способности оснований и фундаментов на практике используется единственная программа «Svai/РC», официально разрешенная для расчетов ГАУ «Управление государственной экспертизы проектной документации и результатов инженерных изысканий в строительстве $\mathrm{PC}(Я) »$. Программа «Svai/PC» была разработана в 90-х годах и соответствует старым нормам (СНиП 2.02.04-88). Между тем многолетняя мерзлота занимает площадь около 10 млн. км², или более $60 \%$ территории России [2] и именно в этой обширной территории расчеты оснований и фундаментов ведутся по СП 25.13330.2012 «Основания и фундаменты на вечномерзлых грунтах». Из этого следует, что актуальность проблемы является достаточно масштабной на территории Российской Федерации. Поэтому мы решили создать программу, которая рассчитывала бы несущую способность оснований фундаментов на многолетнемерзлых грунтах по актуальным на данный момент нормам.

Целью нашей работы является полное автоматизирование расчета оснований фундаментов на многолетнемерзлых грунтах.

Программа «PilePermafrost» закодирована в языке программирования Borland Delphi и может выполнить следующие расчеты:

1. Расчет среднегодовой температуры и глубину сезонного оттаивания и промерзания грунта по методике приложения Г [1];

2. Расчет несущей способности оснований фундаментов при использовании многолетнемерзлых грунтов по принципу I (с сохранением мерзлого состояния грунтов) по СП 25.13330.2012.

Сама программа состоит из трех окон:

На начальном окне (рис.1) рассчитываются необходимые данные, такие как среднегодовая температура и глубина сезонного оттаивания и промерзания грунта, которые используются в дальнейшем для расчета оснований фундаментов в программе.

Исходные данные для расчета несущей способности вводятся в окне «Ввод исходный данных» (рис. 2). В нем задаются данные инженерно-геологических изысканий, тип поверхности фундамента, геометрические характеристики сваи и здания, климатические данные, особенности технологии устройства сваи и другие данные. Для удобства, введенные данные можно отобразить в виде инженерногеологического разреза с помощью кнопки «Нарисовать». 